University of Nebraska - Lincoln

DigitalCommons@University of Nebraska - Lincoln

U.S. Environmental Protection Agency Papers

U.S. Environmental Protection Agency

2004

\title{
The Maturing of the Triad Approach: Avoiding Misconceptions
}

Deana M. Crumbling

U.S. Environmental Protection Agency

Joel S. Hayworth

Hayworth Engineering Science, Inc.

Bradley A. Call

U.S. Army Corps of Engineers

William M. Davis

Tri-Corder Environmental, Inc.

Robert Howe

See next page for additional authors

Follow this and additional works at: https://digitalcommons.unl.edu/usepapapers

Crumbling, Deana M.; Hayworth, Joel S.; Call, Bradley A.; Davis, William M.; Howe, Robert; Miller, David S.; and Johnson, Robert, "The Maturing of the Triad Approach: Avoiding Misconceptions" (2004). U.S. Environmental Protection Agency Papers. 125.

https://digitalcommons.unl.edu/usepapapers/125

This Article is brought to you for free and open access by the U.S. Environmental Protection Agency at DigitalCommons@University of Nebraska - Lincoln. It has been accepted for inclusion in U.S. Environmental Protection Agency Papers by an authorized administrator of DigitalCommons@University of Nebraska - Lincoln. 


\section{Authors}

Deana M. Crumbling, Joel S. Hayworth, Bradley A. Call, William M. Davis, Robert Howe, David S. Miller, and Robert Johnson 


\section{The Maturing of the Triad Approach: Avoiding Misconceptions}

Deana M. Crumbling

Joel S. Hayworth

Bradley A. Call

William M. Davis

Robert Howe

David S. Miller

Robert Johnson
Misunderstandings and misconceptions have arisen as the Triad approach has gained wider application. The Triad initiative's ability to catalyze second-generation cleanup practices will be hampered if inaccurate or incomplete assumptions create persistent confusion about what Triad is or how it works. This article has been prepared by the multi-agency workgroup responsible for articulating the Triad approach and coordinating national Triad efforts. It serves to address some misunderstandings about key Triad concepts. As an aid to those wishing to learn more, a new Web site (the Triad Resource Center, http://www.triadcentral.org) and a new Triad reference document from the Interstate Technology and Regulatory Council (ITRC) are introduced as sources of explanatory information supporting the Triad approach. (C) 2004 Wiley Periodicals, Inc. *

\section{INTRODUCTION}

The Triad approach is a framework developed through the efforts of environmental site professionals to advance site investigation and cleanup practice. Triad is designed around the concept of managing decision uncertainty. It draws on advancing science, technology, and practitioner experience to perfect strategies for making sitework more defensible (both scientifically and legally), more resource-effective, and more responsive to stakeholder expectations. Although Triad is primarily science-based, ample room is provided to address the social, economic, administrative, and legal concerns inherent to contaminated site activities. Within the broader context of uncertainty management, Triad projects explicitly manage data uncertainties (especially uncertainties stemming from pollutant heterogeneity; Crumbling, 2002). Doing so produces better projects, because decision makers get a more accurate picture of site contamination. This picture, or "story," of how contamination occurred, what is happening to it, who might be exposed to it, and what might be done to mitigate that exposure is called a conceptual site model (CSM). An accurate CSM is the basis for confident decisions about risk and remediation. The term "Triad" is used to refer to the three elements used to build an accurate CSM and manage decision uncertainty efficiently and cost-effectively. Those three elements are systematic project planning (builds social capital while identifying the project's end goals and the strategies to achieve them), dynamic work strategies (to implement preapproved decision logic in real time), and real-time measurement technologies (to feed information into the real-time decision-making process).

The Triad approach was developed by experienced practitioners specifically to address the complexities of site investigation and cleanup projects. Our experience is that the many scientific, engineering, regulatory, and social variables encountered in 
Triad fundamentally changes how projects are planned and how data quality is established. the site restoration arena cannot be reduced to simple one-size-fits-all formulas without compromising the quality and cost-effectiveness of project outcomes. We find that projects are most successful when complications such as contaminant heterogeneity and conflicting stakeholder interests are openly acknowledged and accommodated early in project planning. Although the cleanup community is becoming more aware of the phrase "the Triad approach" and of Triad projects, second- or thirdhand exposure to Triad seldom communicates the full range of its scientific and technical underpinnings and its nuances. Explaining Triad concepts accurately, yet succinctly, has proved to be a challenge in communications for the multi-agency workgroup that has spent the past five years articulating the Triad approach. We hope this article and the new resources it introduces will help practitioners better understand the Triad approach to site cleanup.

\section{AVOIDING CONFUSION OVER THE TRIAD APPROACH}

Although Triad projects have much in common with traditional projects, certain Triad practices are very different from traditional patterns of regulatory thinking and project practices. For instance, the concepts of data quality and data representativeness are applied differently in Triad than is typically the case today. There is a tendency for those Triad aspects that seem familiar (like the use of field methods and dynamic strategies) to grab a lot of attention, while Triad concepts that are less familiar (like social capital and the management of sampling uncertainties) seem to escape notice. Ironically, those Triad concepts that are the most novel and most frequently overlooked are actually the ones most important for project success. Triad fundamentally changes how projects are planned and how data quality is established. Because Triad projects adhere to the principle of uncertainty management, seemingly familiar tools (like field analytics) are used in unconventional ways that avoid the pitfalls while extracting the most benefit. When the novel aspects of Triad are not appreciated, people frequently hybridize Triad concepts with more traditional ways of thinking. But hybrid messages cause confusion and problems. We have seen proposals and work plans labeled "Triad" that bear none of the hallmark features of a Triad project. Proposals and reports must be scrutinized to ensure that projects identified as "Triad" actually embody the Triad concepts. Prospective consumers of Triad services need to educate themselves to look for key Triad features. Clarity about the Triad approach is necessary if Triad is to support the modernization efforts of cleanup programs.

The balance of this article will address frequently encountered misperceptions about Triad. Only brief discussion is possible in this article, but more detailed discussion is available. Two new resources are accessible through the Internet:

- One resource is the "Triad Resource Center" (TRC) Web site (http:// www.triadcentral.org) being developed by the multi-agency Triad workgroup. This Web site will be a central repository and resource gateway to access Triad information, find examples of Triad projects, and share lessons learned as Triad practitioners tackle the full range of project types and technical issues. Like the Triad approach itself, the TRC Web site will evolve as new technologies emerge, as experience is gained, and as our knowledge base and repertoire of effective work strategies broadens. This Web site will be the primary commu- 
nication and tracking instrument the U.S. Environmental Protection Agency (US EPA) and its partners will use to support the Triad approach. Reader feedback on the Web site (it is currently in its draft form) is welcome through the "Contact Us" link.

- The other resource this article will reference is a Triad guidance document recently released by the Interstate Technology and Regulatory Council (ITRC) in close collaboration with the multi-agency Triad workgroup. Although not comprehensive, important Triad concepts are reviewed. This document is accessible at http://www.itrcweb.org/SCM-1.pdf.

\section{THE NUMBER-ONE MYTH: TRIAD IS NOTHING NEW}

Aspects of the Triad approach have been practiced in one form or another for many years. This has led many in the environmental cleanup community to observe that the Triad approach is nothing new. This is true in the sense that none of the concepts used in the Triad approach are brand new - there is precedent for all of them. Uncertainty management, social capital, CSMs, multidisciplinary teams, adaptive or dynamic work strategies, real-time measurement technologies, sampling uncertainty - all predate articulation of the Triad approach. However, the fusion of these ideas, strategies, and tools into a fully integrated, internally harmonious framework is clearly different and new (Crumbling et al., 2003). The ways that Triad practitioners weave these together over the life of the project to achieve project efficiency and defensibility is markedly innovative compared to routine practices. But Triad strategies are not experimental; they have been field-tested and refined since the 1980s.

Several features are so fundamental to a Triad project that a claim for Triad cannot be made unless they are present. These include:

- developing clearly articulated goals (for the project), clear statements about what decisions must be made in order to reach those goals, and expressions of how much uncertainty can be tolerated in those decisions;

- establishing metrics by which decision uncertainty can be managed to accepted levels; and

- using collaborative data sets to manage all significant contributions to data uncertainty (both sampling and analytical).

Among other things that differentiate Triad from more traditional approaches, Triad systematic planning shifts several important activities to much earlier in the project life cycle than typical. Those activities include achieving agreement on the exit strategy between regulators and problem holders and developing a robust process for managing, analyzing, and effectively communicating project data.

The newness of Triad becomes apparent whenever a new team embarks on their first project under the guidance of an experienced Triad practitioner. Initial systematic planning efforts are often quite revealing as participants exclaim, "But this isn't the way we do things! Why are you asking us to think about that now? We don't address that until later." They are quite certain "this will never work" because it is so foreign to what they are used to doing. But if they stick with it through their discom-
The newness of Triad becomes apparent whenever a new team embarks on their first project under the guidance of an experienced Triad practitioner. 
The keystone feature of a Triad project is demonstrating that decision uncertainties were identified and managed to the satisfaction of project participants. fort and follow the guidance of the Triad practitioner, toward the end of the project they see how all the pieces fall into place. Then the overall strategy - why it has to be done that way and why it works so much better than the conventional approach-finally makes sense to them. Only after their first project can they see both the "forest" and the "trees." If they give up partway through, they never see the big pictureTriad will remain a mystery.

Another way Triad is different is that it uses language more precisely than commonly observed in the cleanup community. The multi-agency Triad workgroup found we needed to carefully define many seemingly familiar phrases. Terms such as "DQOs," "confirmation," "false positive/false negative," "source area," "definitive," and even the word "sample" sometimes caused confusion in our discussions because they meant different things to different people in different contexts. In line with our key principle of managing uncertainty, the Triad workgroup needed to manage ambiguity in our own communications. We needed a common language before we could articulate Triad concepts within our own multidisciplinary teams. So we developed a glossary for potentially misunderstood terms and defined how they would be used within the context of the Triad approach. We drew from precedent and standard definitions whenever possible. We agreed to strive for clarity in our own usage. It is important that other Triad practitioners make the same effort as Triad disseminates throughout the cleanup community. The glossary is readily accessible on the TRC Web site (www.triadcentral.org). We ask anyone preparing Triad-related documents, guidance, or case studies intended for public dissemination to consult this glossary or confer with workgroup members (who can be contacted through the TRC Web site) to ensure that terminology usage is consistent with workgroup consensus. As with all Triadrelated activities, this glossary is not fixed in stone, but is open to feedback and refinement as cleanup science and Triad practice evolve.

Additional discussion of how Triad is new is available on the Triad Resource Center (TRC) Web site in the Overview and Key Concepts subsection of Triad Management (http:/ /www.triadcentral.org/mgmt/over/index.cfm) and in the Regulatory Information section (http://www.triadcentral.org/reg/index.cfm). Also see pages 1-4 in the ITRC Triad guidance (http://www.itrcweb.org/SCM-1.pdf).

\section{CORRECTING MYTHS ABOUT WHAT CONSTITUTES A TRIAD PROJECT}

We frequently encounter two related myths: "Any project using some field analysis is a Triad project" and "Any project using a dynamic or adaptive work strategy is a Triad project." Both statements are untrue.

The keystone feature of a Triad project is demonstrating that decision uncertainties were identified and managed to the satisfaction of project participants. Dynamic strategies and field analytics are important mechanisms by which this is done efficiently. But both of the mechanisms are often implemented without any attempt to control for uncertainty. If decision uncertainty is not explicitly addressed, the project cannot be considered a Triad project, even though it may share some features of a Triad project. That is not to say that such projects are "bad.” Projects that are incomplete from a Triad standpoint may still be fully acceptable to decision makers and offer many benefits over more traditional project designs. Such projects may also serve as a 
stepping-stone to Triad projects by providing staff and field crews with valuable experience. But the Triad workgroup has deliberately set a high bar (i.e., uncertainty management) for what qualifies as a Triad project. Setting the bar in this way specifies "what" a Triad project will accomplish (i.e., a high-quality project outcome), but allows the "how" to have maximum flexibility and responsiveness to advancing science, experience, and new technologies. Creativity is strongly encouraged, yet accountability is always required.

Making uncertainty management the hallmark feature of a Triad project ensures that Triad projects have the greatest likelihood of achieving a satisfactory outcome in the most efficient way possible. Extensive experience has shown that chances for an equally favorable outcome are reduced if isolated Triad elements are deployed independent of an overarching strategy to manage uncertainty.Implementing a dynamic field activity when project goals are unclear may move fieldwork along faster, but will the information produced meet the regulator's needs? Most likely, important data gaps will be discovered afterwards at the same rate as conventional work plans. Similarly, deploying field methods without multidisciplinary input during planning or using poorly trained analysts is a recipe for generating unreliable data. Only when all essential Triad features are employed is a favorable outcome highly probable. At a minimum, Triad projects will display the following characteristics:

1. A concerted effort to build social capital, achieving clarity and consensus about the desired project outcomes (end goals or exit strategies) so that intended project decisions are clearly articulated (with expressions of what decision errors are tolerable and which are not) before expensive investment in field work begins.

2. A CSM that relates site conditions to the decision process, while anticipating site-specific heterogeneities in contaminant distributions at both macro- and micro-scales.

3. Strategies that test and refine the CSM over the course of the project until there is sufficient confidence in the model to support decision making while avoiding intolerable decision errors.

4. Strategies (such as demonstrations of methods applicability) to identify and control significant sampling and analytical uncertainties in data collection and interpretation.

5. Integration of real-time data collection and management with in-field decision making to the extent feasible so that fieldwork is as efficient as possible.

6. A multidisciplinary team with the skills and knowledge needed to accomplish the above.

Management of decision uncertainty begins by figuring out exactly what the project decisions are. Documentation (i.e., work plans or reports) that is unclear about project objectives is a red flag that Triad's systematic planning process is not being followed. On the other hand, there is no bright-line criterion for how extensive a dynamic strategy needs to be to qualify for a Triad project. Different Triad projects will employ real-time tools and decision-making to varying degrees depending on the needs of the project, the availability of relevant technology tools, and logistical factors such as regulatory, budgetary, contracting and legal constraints and the expertise of the project team.

See additional details on this topic in Triad Overview section of the TRC Web site (http://www.triadcentral.org/over/index.cfm).
Documentation (i.e., work plans or reports) that is unclear about project objectives is a red flag that Triad's systematic planning process is not being followed. 


\section{OBJECTION: ARE YOU SAYING TRIAD IS THE ONLY WAY TO HAVE A SUCCESSFUL PROJECT?}

No. Not every investigation, cleanup, or restoration project needs to be a Triad project to be successful. Non-Triad projects obviously do achieve satisfactory cleanups and demonstrate compliance from a regulatory perspective. But multiple repetitions of fieldwork involving long time frames are the usual means for achieving site closure or reuse. If resources run out before sufficient repetitions can reach completion, the desired project objectives may never be achieved.

What we are saying is that the likelihood of achieving a successful project "faster, better,

Triad minimizes resource expenditures on unattainable goals, leaving more resources to pursue cleanup or reuse alternatives that are viable. and cheaper" is greatly increased by using the Triad approach. In addition, there are times when the severity of site contamination means that project "success" has to be redefined. Site conditions and budgetary constraints may conspire to deny any chance of achieving the "first-choice" site reuse objective, no matter what work strategy is used. Triad is still superior to conventional approaches because those cases will be discovered more quickly. An important part of Triad systematic planning is formulating contingencies and the triggers that activate them. Experienced practitioners can anticipate what problems or issues might arise over the course of a project. Scenarios of "what-if" during planning help structure decision trees that, when triggered during the course of fieldwork, rechannel site activities into more productive options if "plan A" is found to be nonviable. Triad minimizes resource expenditures on unattainable goals, leaving more resources to pursue cleanup or reuse alternatives that are viable.

There are cases where a conventional approach may be more appropriate than Triad. For certain projects, the cooperative, intensive, multidisciplinary nature of Triad systematic planning may be unworkable given the parties involved. The rapid field-based decision-making of a Triad project may be undesirable if a project is highly contentious. It is unwise to force the Triad approach onto an unwilling partner. Significant institutional, budgetary, or regulatory barriers to using the Triad approach still exist, although these should gradually fall as changing mandates, technology acceptance, and resource constraints make repeated mobilizations to fill data gaps unnecessary or unaffordable.

A project team might not be able to run a Triad project if they do not have the needed project management expertise and cannot access an experienced Triad practitioner to guide them. They might be unable to obtain a key technology tool or the expertise to use it properly. Although actually rare (and getting rarer all the time), it is possible that lack of a real-time analytical option for a particular contaminant will block a Triad project.

After evaluating the constraints, even an experienced team may legitimately decide that Triad is not the best option for a specific project. Even if not one decision is made in real time, project quality will still benefit if Triad principles about uncertainty management are applied and a CSM is used to understand contaminant heterogeneity. And most projects benefit from systematic project planning. Sampling and analytical uncertainties still need to be managed in traditional fixed-laboratory data sets in order to develop accurate conceptual site models that support correct site management decisions and effective remedial designs.

For more information, see the TRC Web site in these locations: General FAQs ("Are there any situations where I should not use the Triad?") and the Triad Applicability page (http://www.triadcentral.org/mgmt/clean/applicability/index.cfm). See also pages 38-52 in the ITRC Triad guidance (ITRC, 2003). 


\section{Real-time Measurement Technologies}

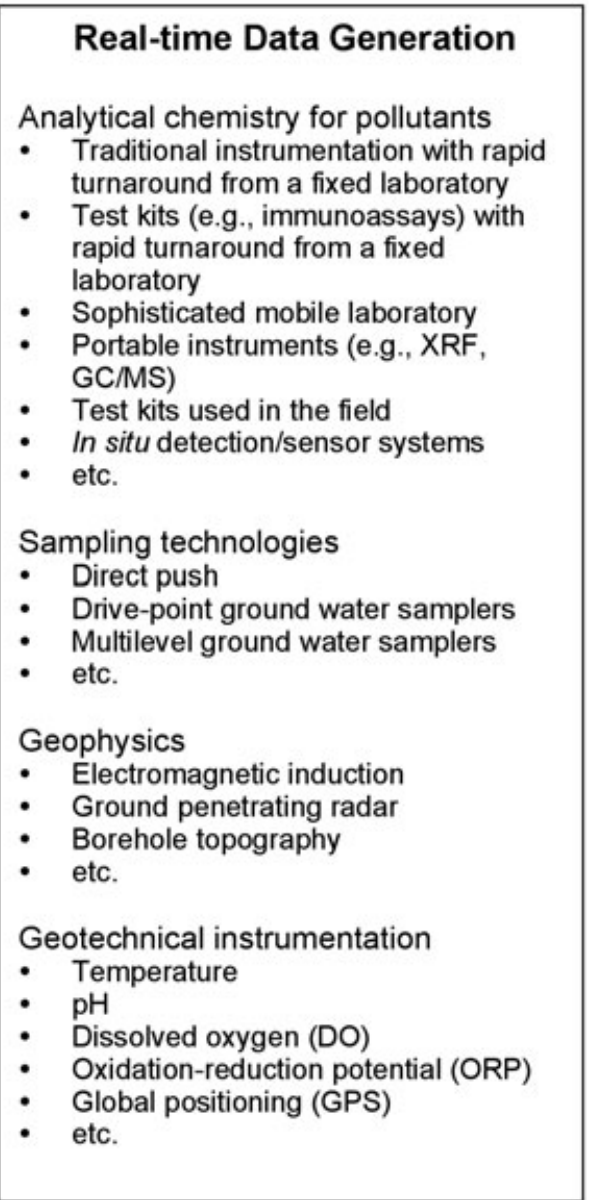

Real-time Data Management
Hardware, software, and
telecommunications options that
support rapid
- Data storage
- Data review (validation and
verification)
- Data assessment/interpretation
Data display/mapping in 2 or 3
dimensions
Development and refinement of
the conceptual site model (CSM)
Dissemination/sharing of data
and reports

Exhibit 1. The variety of tools included in the term real-time measurement technologies

\section{MISCONCEPTION: "REAL-TIME MEASUREMENT TECHNOLOGIES" AND "FIELD ANALYTICS" ARE INTERCHANGEABLE TERMS}

The phrase real-time "measurement technologies" is not interchangeable with the phrase "field analytics." These terms do not mean the same thing. Field analytics are only a subset of the variety of real-time technologies necessary for successful Triad projects.

The inclusive term real-time measurement technologies is deliberately used to encompass the multiple mechanisms available to generate data fast enough to support real-time decision making, as well as tools used to manage that data in real time. The variety of data generation and management options included within the term are displayed in Exhibit 1. Databases and software programs that help the data user to manipulate and display measurement data in real time are vital to test and refine the conceptual site model rapidly enough to feed the decision tree and keep a field crew busy.

Experienced Triad practitioners often invest considerable effort creating real-time measurement systems that integrate data generation and management technologies (and the expertise needed to use them) into a seamless train that then shares the data and the 
... the rapid pace and realtime feedback of Triad projects allows lessons about what works and what doesn't to quickly develop practitioner expertise and regulator proficiency. working CSM in real time (usually via the Internet) among dispersed project participants. Although small, simple Triad projects can manage their data in real time by sticking pins in a map, real-time data management for more complex projects takes considerable up-front planning and an interdisciplinary collaboration.

For more information, see the TRC Web site in these locations: FAQs (Analytical Methods section), Glossary, and the Real-time Measurement Systems page (http://www.triadcentral.org/mgmt/meas/index.cfm). Also, see pages 23-28 in the ITRC Triad guidance (ITRC, 2003).

\section{MYTH: TRIAD PROJECTS VASTLY INCREASE REGULATOR WORKLOAD}

From a total-project perspective, this fear is overblown. It is true that Triad projects do require higher levels of regulatory participation, especially during the planning and fieldwork phases of a project. Restructuring of a regulator's workload would be necessary to handle Triad projects. However, investment of regulator time "up-front" pays greater dividends later by reducing the time necessary to evaluate the resulting project documentation and reporting because of the early project planning and ongoing involvement with data evaluation during the fieldwork. In addition, since a Triad project will be better focused on the decisions important to all team members, including the regulator, the project will be brought to resolution faster (fewer investigation iterations) than a conventional project. This has the associated benefits of reducing the number of cycles for document production and review. Projects are taken "off the books" much faster, so that attention can be devoted to other projects. An added bonus is that the rapid pace and real-time feedback of Triad projects allows lessons about what works and what doesn't to quickly develop practitioner expertise and regulator proficiency.

There is another way that Triad projects make life easier for regulators. An unfortunate result of non-Triad projects is that relationships among the principal stakeholders (client, project team, regulators, and community groups) sometimes begin with wariness and may quickly become adversarial. A goal of the Triad approach is to "shortcircuit" this phenomenon by building social capital — that is, by engaging the principal stakeholders (from the planning process through project completion) in the information and decision-making stream comprising the effort. This is a subtle but important point: the stakeholders do not move from their traditional roles per se; rather, they are provided the opportunity to be aware and contribute at critical junctures of a project as their expertise and insight lead them. Thus, successful systematic planning for a Triad project may involve several iterations of information transfer and discussion through various means (for example, planning team meetings) where initial CSMs, possible contingencies, field tools and approaches, etc., are presented to principal stakeholders for discussion and input. Additionally, during field execution, real-time data and preliminary data interpretations are made available in a user-friendly way (for example, through secure Internet sites dedicated to a project) to principal stakeholders for consideration at their convenience. This free exchange of information empowers all stakeholders and minimizes the development of the "us versus them" mentality that often characterizes stakeholder relationships. In contrast, non-Triad projects often cultivate this mentality by forcing regulators to wait for discrete "data dumps" (for example, when a four-volume work plan arrives on the desk of a regulator after six months of silence from a practitioner, or when a report similarly arrives a year after completion of 
a field effort). The result of this non-Triad behavior is often a painstaking regulatory review where "data gaps" are identified, leading to a replay of the process. When considered in this light, Triad projects clearly reduce regulator workload by considering and addressing regulator concerns early in the planning process, reducing periods of inactivity, and eliminating project "surprises."

At this point in time, no federal or state regulatory agencies require that the Triad approach be used. It would be unwise to do so. Triad projects are multidisciplinary, technically more challenging, and more demanding of interpersonal skills to negotiate up-front resolution of project interests and goals. A great deal of patience, skill, and creativity is needed to circumvent the numerous existing institutional obstacles. The pool of practitioners completing successful Triad projects is growing, but is still small. The US EPA expects adoption of Triad practices to proceed slowly, as an accurate understanding of Triad permeates the cleanup community. The Triad approach is expected to sell itself, as market forces demand more cost-effective, more defensible projects. Site owners and others with financial incentives for faster and more efficient projects can use their purchasing power to create a market draw by shopping for proficient Triad practitioners. Regulatory agencies desiring more confidence in their decisions might suggest that the Triad approach be used, but this runs counter to the usual regulatory stance. Most regulatory agencies see their role as only accepting or rejecting what is proposed, not proactively suggesting alternatives. Many consultants propose only what they know regulators have accepted in the past. Consultants are often reluctant to propose innovative strategies if the regulator might respond negatively. At this time, New Jersey is the only state with a formal policy statement encouraging site owners to propose Triad projects (http://www.state.nj.us/dep/srp/triad/policy.htm). As New Jersey program managers "cut their teeth" on a small number of Triad projects, they are exploring how to address the assorted regulatory and institutional hurdles that inevitably arise. Other states have signaled their willingness to participate in Triad projects, but on a project-specific basis that is less formal than the New Jersey initiative. Although Triad is applicable across the full range of project complexity and site size, Triad projects are run so differently from conventional projects that we do not recommend combining an inexperienced team with a complex project. Unless supported by an experienced Triad practitioner who can steer the team through the pitfalls, we strongly advise that the learning curve be navigated on simple projects.

For more information, see the TRC Web site in these locations: FAQs (Regulatory Acceptance section), Glossary, and the Regulatory Information/Business Process Changes and Regulatory Impacts page (http://www.triadcentral.org/reg/process/index.cfm). Also see Sections 5.0 and 5.1.2 in the ITRC Triad guidance (ITRC, 2003).

\section{MYTH: ANALYTICAL COSTS FOR TRIAD PROJECTS ARE ALWAYS LESS THAN CONVENTIONAL PROJECTS}

Field measurement technologies are generally less expensive than off-site analyses on a "per analysis" basis for most contaminants of concern. However, most Triad projects use high-density sampling and analysis to manage the uncertainty associated with sample heterogeneity. This means that even though per-analysis cost may be less when field measurement technologies are used, the analytical costs associated with a Triad mobilization will often be equivalent to, and occasionally more than, the cost of a single mobilization on a
The Triad approach is expected to sell itself, as market forces demand more cost-effective, more defensible projects. 
Because Triad fieldwork is much more efficient, its life-cycle costs are less than the costs of a conventional investigation and remediation program. . . conventional project for a particular site. Another difficulty with trying to compare costs on a per-sample basis is that field analytical service providers usually charge in terms of daily rates, not per-sample rates. In general, the better the project is planned, the more efficiently field crews will collect and analyze samples. Analyzing more samples per day translates into lower per-sample costs.

A better comparison is to look at costs from a life-cycle perspective. The total analytical costs to get the site to completion will nearly always be significantly reduced using Triad. Life-cycle costs are less because the Triad approach completes projects in fewer field investigation phases. Triad systematic planning minimizes the collection of non-informative data, and dynamic work strategies keep characterization and remediation work focused on project objectives. Because Triad fieldwork is much more efficient, its life-cycle costs are less than the costs of a conventional investigation and remediation program (that produces an equivalent degree of decision confidence). Greater efficiency comes from realtime adaptive work strategies that generate more accurate CSMs from higher densities of field samples taken where there was decision uncertainty that needed to be managed.

For more information, see the TRC Web site in these locations: FAQs (Implementation section), Glossary, and the Scheduling and Load Balancing pages (http:// www.triadcentral.org/mgmt/log/schedule/index.cfm).

\section{MISCONCEPTION: TRIAD PROJECTS HAVE INADEQUATE QUALITY ASSURANCE/OUALITY CONTROL}

Actually the quality assurance performed in Triad projects is more relevant and supportive of defensible project decisions than under traditional scenarios. For example, the Triad approach improves project quality by acknowledging something seldom discussed in traditional quality guidance: the impact of uncertainties stemming from site heterogeneity. Triad projects generally do this by using rapid, high-density measurements (usually provided through field-based techniques) to assess the representativeness of samples and sampling strategies in real time. Predetermined, yet flexible, sampling protocols (prescribed in dynamic work planning documents) allow the investigative activities to converge on the sampling density necessary to reduce data uncertainty to levels supporting the intended site decisions. In addition to sampling-related uncertainty, analytical uncertainty is also carefully assessed and controlled to levels commensurate with data use. A Triad project will have a Quality Assurance Project Plan or similar document that identifies project decisions, intended data uses, relevant uncertainties, and the activities that will be used to manage data uncertainties.

Precision and bias are important data-quality indicators. There has long been a perception that field measurements cannot provide data of adequate analytical quality for site decisions (e.g., remedial design/selection, risk assessment). The Triad approach addresses precision and bias in terms of whether a technique provides data of known quality that is good enough to support correct decisions. Many site decisions can be made with data that has some degree of bias or imprecision, as long as the degree is known and accounted for when the data are interpreted. A key feature of Triad systematic planning is ensuring that the most appropriate methods are selected and modified (if needed) to ensure that the data produced will be reliable, even in the face of difficult matrices. Triad uses a procedure called a "demonstration of methods applicability" to evaluate and tailor the performance of data-generation methods, and to structure the design of quality control (QC) 
checks, ensuring that expected performance is maintained over the course of the project. There are many different field measurement technologies available today, all of which can provide data of known quality as long as the analyst performs proper QC procedures.

Split-sample "confirmation" testing by itself is inadequate to establish that field-generated data are of known quality. Even qualitative techniques such as common colorimetric test kits require some form of calibration and in-field QC checks to ensure they are operating within acceptable limits. When data are used in real time to make decisions, it is critical that the field analyst assess QC data in real time and alert the on-site project manager if any problems arise. Although Triad projects use data to guide decision trees before third-party validation typically occurs, all of the data, including the field data, can be fully validated before major project decisions are irreversibly finalized. Split-sample confirmation by itself can even be misleading. Unless all aspects of the sampling (such as a thoroughly homogenized sample and equivalent sample supports) and analysis (such as sample preparation methods and the analytical principles) chain are equivalent, it is unreasonable to expect sample split analyses by two different analytical methods to provide results that are directly comparable.

Triad projects actually detect and correct analytical mistakes and identify fraud more quickly than traditional projects. Because a key element of Triad is the use of decision making in real time, Triad employs very powerful quality checks not available under traditional analytical strategies. One such check is the real-time comparison between newly generated data and the current CSM. Since the CSM is compiled from multiple lines of evidence, new evidence that does not fit the CSM indicates either (1) the new data is in error or (2) the CSM is still incomplete or is inaccurate. Under a Triad scenario, both possibilities will be evaluated in real time. Scenario \#1 is evaluated by reviewing QC in real time to search for analytical problems and rapidly institute corrective actions. Should data fail to meet the QC requirements established during systematic planning, corrective action will be initiated immediately. Data outside of accepted limits can be discarded, since replacement analysis can be instituted in real time. Additional QC checks can be instituted in real time to manage analytical uncertainty. For example, if all samples are coming out non-detect, the analyst can increase the frequency of QC checks that verify the instrument is able to detect analyte if it were there, controlling for a concern about false negative results. Scenario \#2 can be evaluated by reviewing the current CSM, and revising and retesting the updated CSM with minimal disruption to work flow.

Another powerful quality aspect of Triad projects is their transparency, which is a direct consequence of the real-time involvement of regulators and stakeholders first in planning the project, then in seeing data as it is generated and interpreted to guide decision making. Real-time sharing of data leaves no time for hiding or spinning inconvenient data. Data is made available as it is generated - "warts and all," as Triad practitioners are fond of saying. This transparency builds tremendous trust between parties, augmenting the social capital established during the planning process. The core Triad team will encourage regulators and stakeholders to see themselves as fellow problem solvers striving for a mutually satisfactory resolution.

For more details, see the TRC Web site in these locations: FAQs (Regulatory Acceptance section), Glossary ("focused quality control" and "demonstration of methods applicability”), Regulatory Information/Real-time Data and Regulatory Participation (http://www.triadcentral.org/reg/realtime/index.cfm), Regulatory Information/
Triad projects actually detect and correct analytical mistakes and identify fraud more quickly than traditional projects. 
Risk assessment calculations depend not just on data of known analytical quality, but also on having data of known sampling quality.
Regulatory Concerns Related to Data Management (http://www.triadcentral.org/reg/ concerns/index.cfm), and Real-time Measurement Systems/Key Concepts (http:// www.triadcentral.org/mgmt/meas/key/index.cfm). Also see Sections 2.4 and 2.7 in the ITRC Triad guidance (ITRC, 2003).

\section{MISCONCEPTION: TRIAD-GENERATED DATA WILL BE UNSUITABLE FOR RISK ASSESSMENT}

Some in the environmental community have expressed the concern that data collected during Triad site investigations cannot be used for risk assessment purposes. A suggestion of this nature, while not true, can obviously bias projects away from application of Triad concepts in the mistaken belief that, ultimately, the data will not be useful for risk assessment decisions.

This misconception may be associated with confusion about how real-time measurement techniques are used and the degree of quality control integrated into investigations applying Triad concepts. Briefly, most test kits can never produce data suitable for insertion into risk model calculations, and a Triad project would never use the data for that purpose. Triad investigations will generally gather chemistry data using multiple techniques to address issues like determining sample representativeness, defining analytical uncertainty, and ensuring desired detection limits. The resulting collaborative data set allows creation of an accurate CSM. The CSM then supports the selection of samples that are analyzed using methods appropriate for the generation of risk data. An accurate CSM is essential to establish the representativeness of the data used to make risk predictions. Risk assessment calculations depend not just on data of known analytical quality, but also on having data of known sampling quality. What contaminant population does the data point represent? Is it legitimate to extrapolate a single analytical result on a 1-gram subsample to a volume of 100 cubic yards of soil as part of the risk calculation? Confidence that that data give an accurate picture of site contamination is possible only when sampling variables are controlled and knowledge of contamination variability and extent is captured in the CSM. Triad investigations therefore not only generate acceptable data sets, but they also foster deeper site understanding that supports improved risk assessment predictions and greater decision confidence by all team members, including the risk assessors.

For more details, see the TRC Web site in these locations: FAQs (Dynamic Work Strategies section), and Dynamic Work Strategies/Adaptation/Adaptive Data Collection Strategies (http://www.triadcentral.org/mgmt/dwstrat/adapt/index.cfm). See also Sections 2.4, 2.6, and 2.7 in the ITRC Triad guidance (ITRC, 2003).

\section{MISCONCEPTION: DATA GENERATED DURING A TRIAD PROJECT WILL NOT WITHSTAND LEGAL SCRUTINY}

An often-expressed concern is that data generated with real-time measurement techniques are not adequate for legal purposes. Interpretation of this issue in state courts varies, but principles established in California (The People v. Kelly, 17 Cal.3d 14, 1976) provide three tests for such a data set: (1) the analytical technology is generally recognized in the scientific community; (2) it can be shown that the test method was performed correctly; and (3) the applicability of the method can be substantiated by an ex- 
pert witness. Federal law (William Daubert v. Merrell Dow Pharmaceuticals, Inc., 509 U.S. $579,1993)$ also has established benchmarks to establish the suitability of such data.

These tests include: (1) the technique is valid and tested; (2) the scientific basis of the technology has been subjected to peer review in the professional publications; (3) the rates of potential error associated with the method are known; and (4) the technique has gained general acceptance in the relevant scientific community.

Triad projects place great emphasis on demonstrations of method applicability and QC, on using multiple complementary analytical techniques and converging lines of evidence to support decisions, and on having a work plan that systematically fills data gaps and manages the impacts of heterogeneity through high data densities that test and verify the CSM. All these efforts to explicitly manage all contributions to data uncertainty allow the Triad approach to generate a comprehensive, interlocking appraisal of data quality and defensible project decisions. Although we are not aware of any Triad project that has "gone to court," Triad-generated data and project conclusions should be more legally defensible than projects forced to rely on sparse data points of questionable representativeness (no matter how accurately the 1-gram samples were analyzed).

For more details, see the TRC Web site in these locations: FAQs (Regulatory Acceptance section) and the Regulatory Information/Triad Compatibility with State and Federal Guidelines page (http://www.triadcentral.org/reg/compat/index.cfm). See also Section 5.2.3 in the ITRC Triad guidance (ITRC, 2003).

\section{MYTH: TRIAD SYSTEMATIC PLANNING IS THE SAME AS THE DQO PROCESS}

The systematic planning element of Triad incorporates the thought process promoted by the US EPA's Data Quality Objectives (DQO) process, as well as the U.S. Army Corps of Engineers' (US ACE's) Technical Project Planning (TPP) process and other planning approaches used to address science-based project needs (US ACE, 1998). However, Triad systematic planning goes beyond the DQO process to thoroughly address the following:

- building social capital among stakeholders and assembling a core technical team;

- developing and refining a CSM that addresses contaminant heterogeneity and sampling uncertainties;

- utilizing uncertainty management techniques that include more than just statistical hypothesis testing;

- demonstrating method applicability to ensure sampling and analytical techniques are matched to intended decisions and difficult matrices;

- refining the logistics of a dynamic work strategy;

- planning for real-time data management, assessment, and presentation; and

- procuring appropriate technologies and services.

A team approach and involvement of stakeholders are recommended in DQO guidance, but these take on a higher level of importance if a Triad project is to be successful (US EPA, 2000). Building social capital in the form of trust, consensus, and an efficient
...Triad-generated data and project conclusions should be more legally defensible than projects forced to rely on sparse data points of questionable representativeness... 
Dynamic work strategies often take the form of project-specific flow charts or decision logic guiding the flow of site activities. working relationship is vital to Triad (Pretty, 2003). Identifying project constraints, site reuse issues driving decisions, data needs, and a dynamic work strategy require a level of up-front planning and coordination that is more involved than typically expected for traditional DQO-driven projects.

CSMs also take on a more crucial role in Triad projects than in conventional DQO projects. Rather than simply developing pathway-receptor relationships or geologic and hydrogeologic relationships, Triad CSMs weave these relationships together with the end-goals identified for site cleanup and reuse. Another difference is that Triad projects use the CSM as a tool to understand what contaminant populations are present as a consequence of contaminant release and fate mechanisms that produce macro- and microscale heterogeneity.

The types of studies now called "demonstrations of methods applicability" (DMAs) are recommended in the US EPA's SW-846 methods manual for the waste programs (US EPA, 1996). They are not specifically addressed as part of the DQO process, although they could be viewed as part of its Step 7 (optimizing the design for obtaining data). Up-front evaluations of method performance can be essential for Triad projects that use field-based methods, because these methods can be less selective than fixed lab methods. DMAs also control for analytical uncertainty when difficult matrices challenge the performance analytical methods. Both standard fixed lab methods and field methods should be evaluated for analytical interferences.

Refinement of a dynamic work strategy is an essential element of Triad systematic planning that is not identified in the DQO process, since it includes activities that extend beyond the data collection process. Dynamic work strategies often take the form of project-specific flow charts or decision logic guiding the flow of site activities. One of these activities is interpretation of data in real time to refine the CSM in the field. This is no simple matter. This element must be carefully planned well before field deployment, or a Triad project will quickly fall apart. Commercial and publicly available software packages that assist real-time data management are multiplying rapidly. Skilled operators are needed to use them, but companies are emerging that specialize in providing the services needed to produce highly sophisticated GIS/3D CSM visualization graphics from data given to them electronically. Finally, procurement considerations are explicitly considered part of the systematic planning process under the Triad approach. Involvement of a procurement specialist early in the planning process avoids problems later on. Coordination with equipment vendors and subcontractors, identification of contingency plans, and cost ceilings are part of Triad planning since they impact workplan design.

More extensive discussion can be found on the TRC Web site in all locations describing various components of systematic planning, as well as the Regulatory Acceptance FAQ "How is Triad related to the DQO process?" See also Sections 2.5 and 3.1 in the ITRC Triad guidance (ITRC, 2003).

\section{MISCONCEPTION: "TRIAD" APPEARS AS AN ACRONYM}

We often see the word "Triad" written in all capital letters. The word "Triad" in "the Triad approach" is not an acronym, and it should not be written to appear as one. The reason for choosing the word "Triad" was to intuitively suggest the three primary elements that achieve cost-effective, confident projects. When people first see the word written as TRIAD, they think it is an acronym and wonder what the hidden meaning is. 


\section{SUMMARY}

The Triad approach was developed by cutting-edge practitioners to advance the state of the art and science of site remediation practice. Triad is built from the "ground up" from the practices proven empirically to work in the field. Triad's impact on the remediation industry is expected to extend beyond practitioners, since site practices are tightly linked to regulatory frameworks and business models. All must move forward together if next-generation practices are to be adopted as routine. Communicating Triad concepts would be easier if Triad were reducible to rote checklists or rules of thumb. But that is not possible since the subtleties within the Triad approach are simply a reflection of those that remediation professionals must face in order to do their jobs well. Given the apparent complexity of Triad, it is inevitable that misperceptions will arise. It is important that the industry not become confused. Keeping in mind Triad's central theme should help: All Triad activities are anchored in the management of decision uncertainty. By applying this single unifying principle broadly across boundaries of technical disciplines and social interests, Triad can help to forge bridges where disconnects exist among the scientific, engineering, policy, and social imperatives governing site investigation, cleanup, and restoration.

\section{REFERENCES AND RELEVANT DOCUMENTS}

Crumbling, D. M. (2002). In search of representativeness: Evolving the environmental data quality model. Quality Assurance, 9(3-4), 179-190. Retrieved July 19, 2004, from http://cluin.org/download/char/ dataquality/dcrumbling.pdf

Crumbling, D. M., Griffith, J., \& Powell, D. M. (2003). Improving decision quality: Making the case for adopting next generation site characterization practices. Remediation, 13(2), 91-111. Retrieved July 19, 2004, from http://cluin.org/download/char/spring2003v13n2p91.pdf

Federal Remediation Technologies Roundtable (FRTR). (2004). On-line Triad resource center (TRC). Retrieved July 19, 2004, from http://www.triadcentral.org

Interstate Technology and Regulatory Council. (ITRC). (2003). Technical and regulatory guidance for the Triad approach: A new paradigm for environmental project management (SCM-1). Prepared by the ITRC Sampling, Characterization and Monitoring Team. Retrieved July 19, 2004, from http://www.itrcweb.org/SCM-1.pdf

Pretty, J. (2003). Social capital and the collective management of resources. Science, 302, 1912-1914.

U.S. Army Corps of Engineers (US ACE). (1998). Environmental quality: Technical project planning (TPP) process (Engineering Manual 200-1-2). Washington, DC: Author. Retrieved July 19, 2004, from http://www.usace.army.mil/inet/usace-docs/eng-manuals/em200-1-2/toc.htm

U.S. Environmental Protection Agency. (US EPA). (1996). Test methods for evaluating solid waste, physical/chemical methods (SW-846). Retrieved July 19, 2004, from http://www.epa.gov/SW-846/index.htm (See Preface and Chapter 2).

U.S. Environmental Protection Agency (US EPA). (2000). Guidance for the data quality objectives process (EPA QA/G-4). EPA/600/R-96/055. Washington, DC: Author. Retrieved July 19, 2004, from http:// www.epa.gov/quality/qs-docs/g4-final.pdf 
U.S. Environmental Protection Agency (US EPA). (2004). Improving sampling, analysis, and data management for site investigation and cleanup (Fact sheet). EPA-542-F-04-001a. Washington, DC: Author. Retrieved July 19, 2004, from http://cluin.org/download/char/2004triadfactsheeta.pdf

Deana M. Crumbling has worked in the hazardous waste site cleanup arena over the past 14 years. Ms. Crumbling has worked for the US EPA since 1997. Her duties include synthesizing current and emerging strategies and technologies to promote efficient site characterization and remediation. She is an analytical chemist with clinical, industrial, and research experience. She holds a BS in biochemistry, a BA in psychology, and an MS in environmental science.

Joel S. Hayworth has over 18 years of experience in the field of hazardous waste site assessment and remediation. Prior to forming Hayworth Engineering Science, Inc. in 2000, Dr. Hayworth worked at the Tennessee Valley Authority Engineering Laboratory, the Air Force Research Laboratory, and Applied Research Associates. He holds a BS in geophysics, an MS in hydrogeology, and a PhD in hydrology. He is also a professional engineer registered in the state of Florida.

Bradley A. Call is a senior environmental engineer with the U.S. Army Corps of Engineers and is a registered professional. He is a Corps Innovative Technology Advocate in the areas of applying field analytical techniques to site investigation, using environmental data management and analysis software, and employing innovative remedial technologies. Mr. Call has a BS in civil engineering and an MS in environmental engineering.

William M. Davis was formerly with the U.S. Army Corps of Engineers, where he participated in developing the Site Characterization and Analysis Penetrometer System (SCAPS) and sensors for in situ contaminant detection. Dr. Davis is currently with Tri-Corder Environmental, Inc. offering turnkey Triad services. He holds a BS in chemistry and an MS in analytical chemistry. His PhD in water chemistry involved applying advanced analytical chemistry techniques to investigate the interaction of pollutants with natural matrices.

Robert Howe has 20 years of experience in environmental sciences and 15 years of experience in implementation of environmental restoration projects. As a geochemist and project manager, he has participated in hundreds of investigation and cleanup projects, utilizing a wide variety of field-based measurement technologies and sampling schemes. Mr. Howe supports the US EPA's Triad efforts and the Brownfields Technical Support Center with numerous Triad work products and training course deliveries.

David S. Miller has 20 years of experience in civil, geological, and environmental engineering. As manager of the Geosciences and Information Technology Section in the Environmental Assessment Division at Argonne National Laboratory, Dr. Miller provides environmental assessment, decision support, and policy expertise to a wide range of federal agencies. He holds a BA in history, a BS in geology, a BS in civil engineering, and an MSE and $\mathrm{PhD}$ in environmental engineering, and is a registered geologist and professional engineer.

Robert Johnson is with the Environmental Assessment Division at Argonne National Laboratory. His area of expertise is adaptive sampling program design for hazardous waste site remediation and environmental emergency response. Over the last decade, Dr. Johnson designed dynamic field data collection activities at more than 20 federal facilities. He has a BA in mathematics, an MS in environmental engineering, and a $\mathrm{PhD}$ in agricultural engineering. 